\title{
Recursos humanos, financeiros e materiais de atletas de basquetebol nas categorias de base e a percepção dos treinadores sobre a formação dos atletas
}

CDD. 20.ed. 796.073

796.32

http://dx.doi.org/10.1590/1807-55092014000300491

\author{
Cleiton Pereira REIS* \\ Luiz Carlos Couto de Albuquerque MORAES* \\ Márcia Cristina Custódia FERREIRA* \\ Franco NOCE* \\ Varley Teoldo da COSTA* \\ *Escola de Educação
Física, Fisioterapia e
Terapia Ocupacional,
Universidade Federal
de Minas Gerais.
}

\section{Resumo}

0 objetivo deste estudo foi analisar os recursos humanos, financeiros e materiais de atletas de basquetebol nas categorias de base e a percepção dos treinadores sobre estes recursos no processo de formação do atleta. A amostra do estudo foi composta por: 47 atletas de categoria sub-19 anos de Minas Gerais e os respectivos treinadores e 47 atletas profissionais. 0s instrumentos utilizados foram: Questionário sobre o Contexto da Prática para Atletas de Basquetebol (QCP-Basq), Versão Recursos para o Treinamento e entrevista semiestruturada. Com base nos resultados foi possivel entender que os atletas profissionais treinaram em instituições com mais recursos desde a iniciação esportiva em comparação aos atletas da categoria sub-19 anos de Minas Gerais. Os treinadores de Minas Gerais indicam precariedade na estruturação dos recursos na formação do jovem atleta e ressaltam que há dificuldade em aproveitar 0 jogador que se destaca nas categorias de base nas equipes profissionais do Estado.

Palavras-chave: Basquetebol; Atletas; Educação física; Treinamento.

\section{Introdução}

A compreensão dos fatores que fazem um iniciante se tornar um "expert" é de fundamental importância nos estudos da "expert" performance. ERICsson et al. ${ }^{1}$ e ERICSSON ${ }^{2}$ verificaram que para um indivíduo alcançar o topo de seu desempenho este precisa treinar por longos anos, em um contexto que o proporcione os melhores recursos possíveis. No contexto esportivo é necessário a compreensão de como se procede a trajetória do atleta, desde a iniciação esportiva até sua possível consagração, e quais os recursos ele teve a disposição para o seu desenvolvimento ${ }^{3-4}$.

Côté et al. ${ }^{5}$ ao estudarem ginastas de alto rendimento do Canadá, verificaram que o desenvolvimento destas atletas é fomentado dentro de um sistema holístico (modelo do treinador). Além de anos de treinamento, apoio dos pais e alto grau de motivaçáo para a prática esportiva, se faz necessário uma infraestrutura de elevado padrão para o desenvolvimento destes atletas. Tal infraestrutura pode ser dividida em: recursos humanos, como: a presença de treinadores, auxiliar técnico, fisioterapeuta, médico e profissional da área de psicologia do esporte no cotidiano esportivo do atleta; recursos materiais como: instalaçóes esportivas, espaço para o treinamento e material esportivo e recursos financeiros como: salário, bolsa de estudo e vale-transporte fornecidos aos atletas ${ }^{2-4}$.

Além do estudo de Côté et al. ${ }^{5}$, pode-se destacar outros estudos que mostraram como é importante o atleta ter a disposiçáo recursos adequados para que a excelência do desempenho esportivo seja alcançada. JoHnson et al. ${ }^{6}$ verificaram que atletas "experts" de natação dos Estados Unidos, mesmo aqueles que não foram considerados como talentosos para o esporte na iniciação, conseguiram atingir a excelência esportiva através da prática deliberada 
em centros de treinamento de ponta. No contexto brasileiro destacam-se o estudo de Ferreira et al. ${ }^{3}$, com nadadores; Nunomura e Oliveira ${ }^{7}$, SCHIAVON e $\mathrm{PAES}^{8}$ com atletas da ginástica artística.

O basquetebol é um esporte que exige um alto grau de treinamento dos atletas para que se alcance um desempenho de excelência. Para isso, atletas devem estar bem condicionados nos aspectos físico, tático, técnico e psicológico. Tal situação, comum aos atletas de alto rendimento, é atingida depois de vários anos de prática em uma estrutura adequada de treinamento ${ }^{3,5}$.

Geralmente, o atleta desta modalidade começa a praticar o esporte por volta dos 10 a 12 anos. No Brasil, a Confederação Brasileira de BasketBALL $^{9}$ divide a categoria de base por faixas-etárias, divisóes de equipes feitas a partir do ano de nascimento dos atletas. Estas categorias abrangem desde o sub-12 anos (minibasquetebol), no qual o aro é mais baixo e a bola é menor, até a categoria adulta.

BLOOM $^{10}$ e CôTÉ ${ }^{11}$ classificam o desenvolvimento esportivo em três fases: fase de experimentação ou anos iniciais de aprendizagem, até os 13 anos de idade, que corresponde à iniciação esportiva das crianças; fase de especialização ou anos intermediários de aprendizagem, dos 14 aos 15 anos de idade, período no qual o adolescente é fisgado por um esporte específico e o compromisso com treinamentos e jogos

\section{Método}

Esta pesquisa se encontra dentro das normas estabelecidas pelo Conselho Nacional de Saúde e foi aprovada pelo Conselho de Ética na Pesquisa (COEP) da Universidade Federal de Minas Gerais sob o número de protocolo ETIC 0226.0.203.00011 para a aplicação do questionário, e ETIC 0454.0.2003.000-11 para aplicação das entrevistas.

\section{Amostra}

Participaram deste estudo 94 atletas e cinco treinadores de basquetebol, ambos do sexo masculino. Sendo 47 atletas, da categoria sub-19 anos que disputavam competiçóes federadas, promovidas pela Federaçáo Mineira de Basketball (com média de idade de $18,36 \pm 0,96$ anos) e seus respectivos cinco treinadores (com média de idade de 36,08 $\pm 11,92$ anos). Também foram avaliados 47 atletas profissionais com média de idade de 27,03 \pm 5,63 anos, pertencentes aumenta consideravelmente; e após os 16 anos, fase de investimento ou anos finais de aprendizagem, fase que o atleta já tem condiçóes físicas e psicológicas para começar a praticar o esporte de forma deliberada.

Nesta última fase da categoria de base, dos 18 aos 19 anos, categoria sub-19 anos, o atleta se entrega a um treinamento mais aprofundado do basquetebol. Esta categoria representa a última etapa antes do atleta de basquetebol se tornar profissional. Vale lembrar que os recursos para o treinamento disponíveis aos atletas aumentam em número e em qualidade com o passar das fases de desenvolvimento ${ }^{10-11}$. O atleta, para conseguir sair da categoria de base e atingir o profissionalismo, precisa estar inserido, desde a iniciação, em um contexto favorável que promova a estes indivíduos recursos humanos, materiais e financeiros adequados para o treinamento ${ }^{3,7,11}$.

Visto o contexto exposto nos parágrafos anteriores, faz-se necessário identificar os recursos que atletas da categoria de base do basquetebol brasileiro têm a disposição, assim como analisar a percepção que treinadores possuem sobre o assunto. Sendo assim, o objetivo deste estudo foi analisar os recursos humanos, financeiros e materiais de atletas de basquetebol nas categorias de base e a percepção dos treinadores sobre estes recursos no processo de formação dos atletas.

a cinco equipes participantes da Liga Nacional de Basquetebol (NBB- Novo Basquete Brasil).

\section{Instrumentos}

Questionário sobre o Contexto da Prática para Atletas de Basquetebol (QCP-Basq), Versão Recursos para o Treinamento

O Questionário sobre o Contexto da Prática para Atletas de Basquetebol, versão recursos para o treinamento, tem como suporte teórico o modelo do treinador ${ }^{5}$ e os modelos de desenvolvimento de talentos de BLOoM ${ }^{10}$ e Côté ${ }^{11}$. Tal instrumento mede, no período dos seis aos 19 anos, os recursos de treinamento fornecidos aos atletas. O questionário é composto por duas partes: características pessoais e recursos para o treinamento. Este instrumento foi aplicado aos atletas da categoria sub-19 
anos de Minas Gerais e aos atletas profissionais. Outros estudos com este viés qualitativo têm sido desenvolvidos em várias modalidades esportivas para avaliar os recursos para o treinamento que atletas têm a disposição para o treinamento ${ }^{3,5}$.

\section{Entrevista Semiestruturada}

A entrevista semiestruturada foi realizada com os treinadores federados da categoria sub-19 anos em Minas Gerais. O objetivo desta etapa do estudo foi avaliar a percepçáo dos mesmos a respeito do processo de formação dos atletas de basquetebol na categoria de base. O roteiro da entrevista semiestruturada foi elaborado tendo como principais eixos temáticos: recursos humanos, materiais e financeiros que os atletas por eles comandados tinham a disposição.

A técnica de entrevista semiestruturada para a coleta de dados tem sido utilizada como uma ferramenta para entender de forma holística o processo de desenvolvimento de atletas rumo ao desempenho de excelência ${ }^{3,5-6}$. Este tipo de instrumento ao privilegiar a fala de atores sociais, permite atingir um nível de compreensão que se torna acessível por meio de discursos, sendo apropriada para investigação cujo objetivo é conhecer como um grupo de pessoas percebe um determinado fenômeno social ${ }^{12-13}$.

As perguntas foram previamente listadas, mas apenas como um roteiro. Este tipo de instrumento é caracterizado pela flexibilidade, pois o pesquisador estabelece a ordem das questóes de acordo com o andamento da entrevista ${ }^{3,6}$. Foi utilizado, para a gravação das entrevistas, um aparelho da marca Philips Digital Pocket Meno ${ }^{\oplus}$. Depois as entrevistas foram transcritas com ajuda de um pedal da marca Philips Transcription Set ${ }^{\circ}$, que permitia o controle da gravação sem o uso das mãos.

Tanto o conteúdo do Questionário sobre o Contexto da Prática para Atletas de Basquetebol (QCP-Basq.), Versão Recursos para o Treinamento e entrevista semiestruturada foram validados através da técnica de "expert rating", passando pela análise de peritos: especialistas em Psicologia do esporte e Treinadores de Basquetebol. Todos os itens avaliados tiveram a concordância dos peritos acima de $80 \%{ }^{13-14}$.

\section{Procedimentos}

A Confederação Brasileira de Basketball enviou uma carta aos pesquisadores apoiando o presente estudo. De posse de tal carta, foi feito um primeiro contato com os diretores de basquetebol das equipes da categoria sub-19 anos e profissional, para a obtenção do aval institucional para a realização do estudo. Foram agendadas datas para a coleta de dados com cada equipe. A realização do estudo aconteceu em um momento que não atrapalhou a rotina de treinamento e de jogos.

Tanto a aplicação do questionário aos atletas quanto as entrevistas com os treinadores aconteceram em um local reservado. Este local garantiu, aos indivíduos, silêncio e conforto. Os instrumentos de pesquisa foram aplicados por um único pesquisador (questionário e entrevistas), que forneceu todas as explicaçóes necessárias para o bom entendimento por parte dos sujeitos. As transcriçóes literais das entrevistas foram enviadas aos cinco treinadores $\mathrm{da}$ categoria sub-19 anos de Minas Gerais, juntamente com uma carta, que foi assinada e reenviada aos pesquisadores, como forma de consentimento à veracidade dos dados.

\section{Análise dos dados}

Foi aplicado o teste de qui-quadrado para se comparar os recursos para o treinamento entre atletas da categoria sub-19 anos de Minas Gerais e atletas profissionais. O nível de significância adotado foi de $5 \%$. As análises foram realizadas no programa estatístico SPSS for Windows , versão 17.0.

A análise do conteúdo das entrevistas feitas com os treinadores seguiu as diretrizes estabelecidas nos estudos de Côté et al. ${ }^{5}$, Johnson et al. ${ }^{6}$, Ferreira et al. ${ }^{3}$. As entrevistas foram divididas em pequenos trechos, ou miniunidades, denominadas "meaning units" (MUs). Elas são consideradas as menores partes compreensíveis de um texto que expressam uma ideia ou informaçãa ${ }^{15}$. Para prevalecer o anonimato dos cinco entrevistados, cada MU foi identificada com a letra $\mathrm{T}$ (treinador), e um número de 1 a 5 . As MUs foram classificadas em três categorias: recursos humanos, materiais e financeiros. 


\section{Resultados}

A seguir, foram feitas análises dos recursos que os atletas profissionais e da categoria sub-19 anos de Minas Gerais tiveram para treinar, em cada faixa etária da categoria de base. Considerou-se apenas os atletas que treinaram em cada faixa-etária, o que dá um panorama dos recursos fornecidos pelas instituiçôes esportivas. Dos seis aos 13 anos, náo houve diferença significativa entre os atletas que tiveram ou náo o recurso: auxiliar técnico e médico. A maior parte dos atletas profissionais não possuía os outros recursos descritos (TABELA 1).

Entre os 14 e 15 anos, nos quesitos: salário, auxílio financeiro, profissional da área de psicologia do esporte e nutricionista, a maioria dos atletas profissionais não tiveram tais recursos. Porém a maior parte deles treinava com o apoio de um preparador físico. Nos outros recursos não houve prevalência (TABELA 2).

TABELA 1 - Distribuição dos atletas quanto aos recursos humanos e financeiros para o treinamento de atletas profissionais de basquetebol entre os seis e 13 anos de idade e valores do teste de qui-quadrado.

${ }^{*} p<0,05$.

${ }^{*} p<0,05$.

\begin{tabular}{lccccc}
\hline Recursos para o treinamento & sim & náo & total & $\chi^{\mathbf{2}}$ & p \\
\hline Preparador físico & $(29,41 \%)$ & $(70,59 \%)$ & 34 & 5,765 & $*_{0}, 016$ \\
Salário & $(8,82 \%)$ & $(91,18 \%)$ & 34 & 23,059 & $*_{<} 0,001$ \\
Auxílio financeiro (bolsa) & $(17,65 \%)$ & $(82,35 \%)$ & 34 & 14,235 & $*_{<} 0,001$ \\
Fisioterapeuta & $(32,35 \%)$ & $(67,65 \%)$ & 34 & 4,235 & $* 0,04$ \\
$\begin{array}{l}\text { Profissional da área } \\
\text { de psicologia do esporte }\end{array}$ & $(8,82 \%)$ & $(91,18 \%)$ & 34 & 23,059 & $*_{<}<0,001$ \\
Auxiliar técnico & $(55,88 \%)$ & $(44,12 \%)$ & 34 & 0,471 & 0,493 \\
Médico & $(44,12 \%)$ & $(55,88 \%)$ & 34 & 0,471 & 0,493 \\
Nutricionista & $(14,71 \%)$ & $(85,29 \%)$ & 34 & 16,941 & $*<0,001$ \\
$\begin{array}{l}\text { Bolsa de estudo pelo fato } \\
\text { de jogar basquetebol }\end{array}$ & $(29,41 \%)$ & $(70,59 \%)$ & 34 & 5,765 & $* 0,016$ \\
Transporte para treinos & $(26,47 \%)$ & $(73,53 \%)$ & 34 & 7,529 & $* 0,006$ \\
\hline
\end{tabular}

TABELA 2 - Distribuição dos atletas quanto aos recursos humanos e financeiros para o treinamento de atletas profissionais de basquetebol entre os 14 e 15 anos de idade e valores do teste de qui-quadrado.

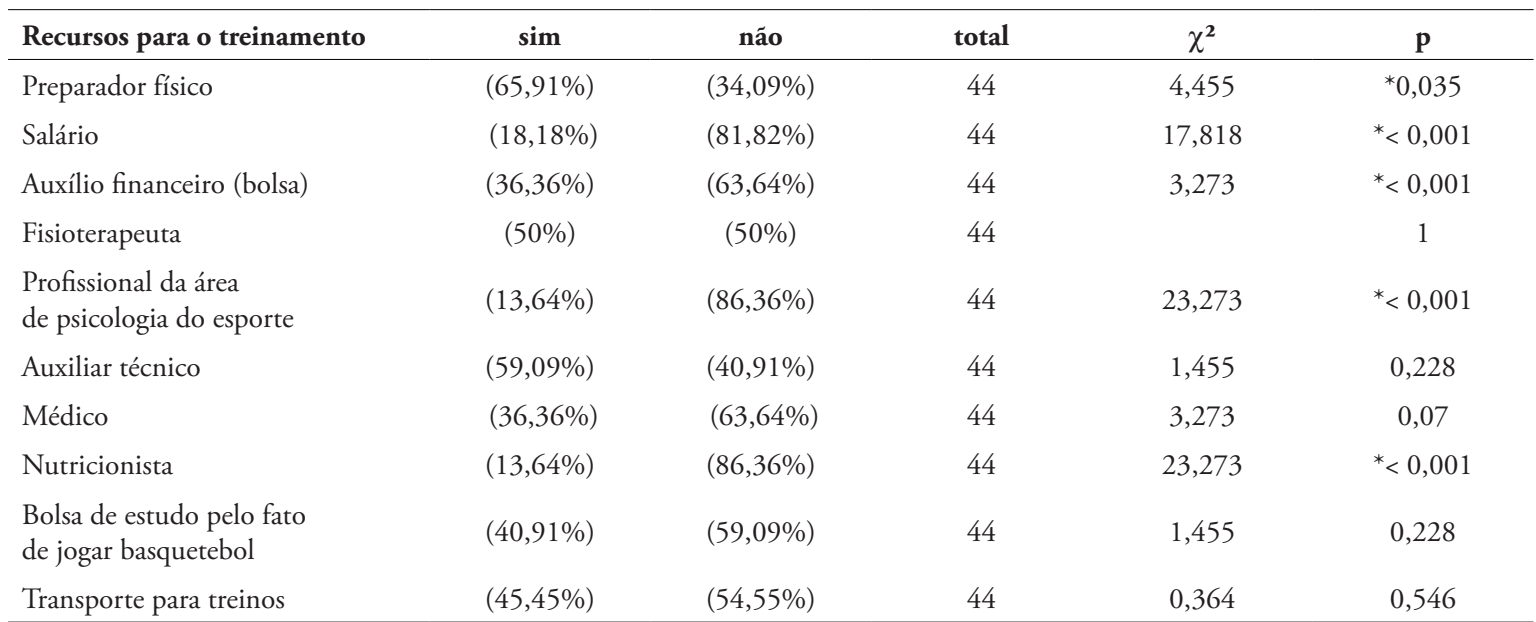

A maioria dos atletas profissionais possuiu os recursos: preparador físico, salário, fisioterapeuta, auxiliar técnico, médico na faixa etária dos 16 aos 19 anos. Porém, a menor parte teve acesso a um profissional da área de psicologia do esporte. Para os outros recursos, não houve prevalência. Todos os atletas profissionais já treinavam nesta fase (TABELA 3).
Em relação aos atletas da categoria sub-19 anos de MG, na faixa etária seis a 13 anos, não dá para se dizer que a maior parte deles teve acesso ao recurso preparador físico. A maior parte dos atletas não conseguiu acesso aos outros recursos descritos (TABELA 4). 
TABELA 3 - Distribuição dos atletas quanto aos recursos humanos e financeiros para o treinamento de atletas profissionais de basquetebol entre os 16 e 19 anos de idade e valores do teste de qui-quadrado.

\begin{tabular}{|c|c|c|c|c|c|}
\hline Recursos para o treinamento & sim & náo & total & $\chi^{2}$ & $\mathbf{p}$ \\
\hline Preparador físico & $(89,36 \%)$ & $(10,64 \%)$ & 47 & 29,128 & $*^{*}<0,001$ \\
\hline Salário & $(76,60 \%)$ & $(23,40 \%)$ & 47 & 13,298 & $*_{<}<0,001$ \\
\hline Auxílio financeiro (bolsa) & $(63,83 \%)$ & $(36,17 \%)$ & 47 & 3,596 & 0,058 \\
\hline Fisioterapeuta & $(85,11 \%)$ & $(14,89 \%)$ & 47 & 23,17 & $*^{*}<0,001$ \\
\hline $\begin{array}{l}\text { Profissional da área } \\
\text { de psicologia do esporte }\end{array}$ & $(23,40 \%)$ & $(76,60 \%)$ & 47 & 13,298 & $*_{<}<0,001$ \\
\hline Auxiliar técnico & $(82,98 \%)$ & $(17,02 \%)$ & 47 & 20,477 & $*<0,001$ \\
\hline Médico & $(70,21 \%)$ & $(29,79 \%)$ & 47 & 7,681 & $* 0,006$ \\
\hline Nutricionista & $(42,55 \%)$ & $(57,45 \%)$ & 47 & 1,043 & 0,307 \\
\hline $\begin{array}{l}\text { Bolsa de estudo pelo fato } \\
\text { de jogar basquetebol }\end{array}$ & $(40,43 \%)$ & $(59,57 \%)$ & 47 & 1,723 & 0,189 \\
\hline Transporte para treinos & $(46,81 \%)$ & $(53,19 \%)$ & 47 & 0,191 & 0,662 \\
\hline
\end{tabular}

TABELA 4 - Distribuição dos atletas quanto aos recursos humanos e financeiros para o treinamento atletas de basquetebol da categoria sub-19 anos de Minas Gerais entre os seis e 13 anos de idade e valores do teste de qui-quadrado.

\begin{tabular}{|c|c|c|c|c|c|}
\hline Recursos para o treinamento & $\operatorname{sim}$ & náo & total & $\chi^{2}$ & $\mathbf{p}$ \\
\hline Preparador físico & $(34,78 \%)$ & $(65,22 \%)$ & 23 & 2,13 & 0,144 \\
\hline Salário & $(0 \%)$ & $(100 \%)$ & 23 & & \\
\hline Auxílio financeiro (bolsa) & $(26,09 \%)$ & $(73,91)$ & 23 & 5,26 & ${ }^{*} 0,022$ \\
\hline Fisioterapeuta & $(8,70 \%)$ & $(91,30 \%)$ & 23 & 15,7 & $*_{<}<0,001$ \\
\hline $\begin{array}{l}\text { Profissional da área } \\
\text { de psicologia do esporte }\end{array}$ & $(4,35 \%)$ & $(95,65 \%)$ & 23 & 19,2 & $*_{<}<0,001$ \\
\hline Auxiliar técnico & $(26,09 \%)$ & $(73,91 \%)$ & 23 & 5,26 & ${ }^{*} 0,022$ \\
\hline Médico & $(21,74 \%)$ & $(78,26 \%)$ & 23 & 7,35 & ${ }^{*} 0,007$ \\
\hline Nutricionista & $(0 \%)$ & $(100 \%)$ & 23 & & \\
\hline $\begin{array}{l}\text { Bolsa de estudo pelo fato } \\
\text { de jogar basquetebol }\end{array}$ & $(30,43 \%)$ & $(69,57 \%)$ & 23 & 3,52 & 0,061 \\
\hline Transporte para treinos & $(13,04 \%)$ & $(86,96 \%)$ & 23 & 12,6 & $*<0,001$ \\
\hline
\end{tabular}

Na faixa etária 14 a 15 anos, não houve prevalência nos recursos: preparador físico e auxiliar técnico. A maior parte dos atletas não conseguiu acesso aos outros recursos (TABELA5).

Entre os 16 e 19 anos, a maior parte dos atletas recebia os recursos: preparador físico, fisioterapeuta, nutricionista e transporte para os treinos, cedido pela instituição esportiva. A maior parte deles continuou não tendo o acesso ao profissional da área de psicologia do esporte. Para os outros recursos, não houve prevalência (TABELA 6).

$\mathrm{Na}$ comparação entre os grupos, por fase de treinamento, em nenhum caso, os atletas da categoria sub-19 nos de MG tiveram mais recursos para o treinamento que os atletas profissionais (TABELAS 7,8,9). A TABELA 7 mostra a comparação dos recursos para o treinamento entre os grupos entre os seis e 13 anos.

Já a TABELA 8 mostra a comparação entre os recursos para o treinamento entre os grupos entre os 14 e 15 anos de idade.

A TABELA 9 mostra a comparação dos recursos para o treinamento entre os atletas da categoria sub-19 anos de MG e os profissionais entre os 16 e 19 anos. 
Reis CP, et al.

TABELA 5 - Distribuição dos atletas quanto aos recursos humanos efinanceiros para otreinamento de atletas debasquetebol da categoria sub-19 anos de Minas Gerais entre os 14 e 15 anos de idade e valores do teste de qui-quadrado.

$p<0,05$

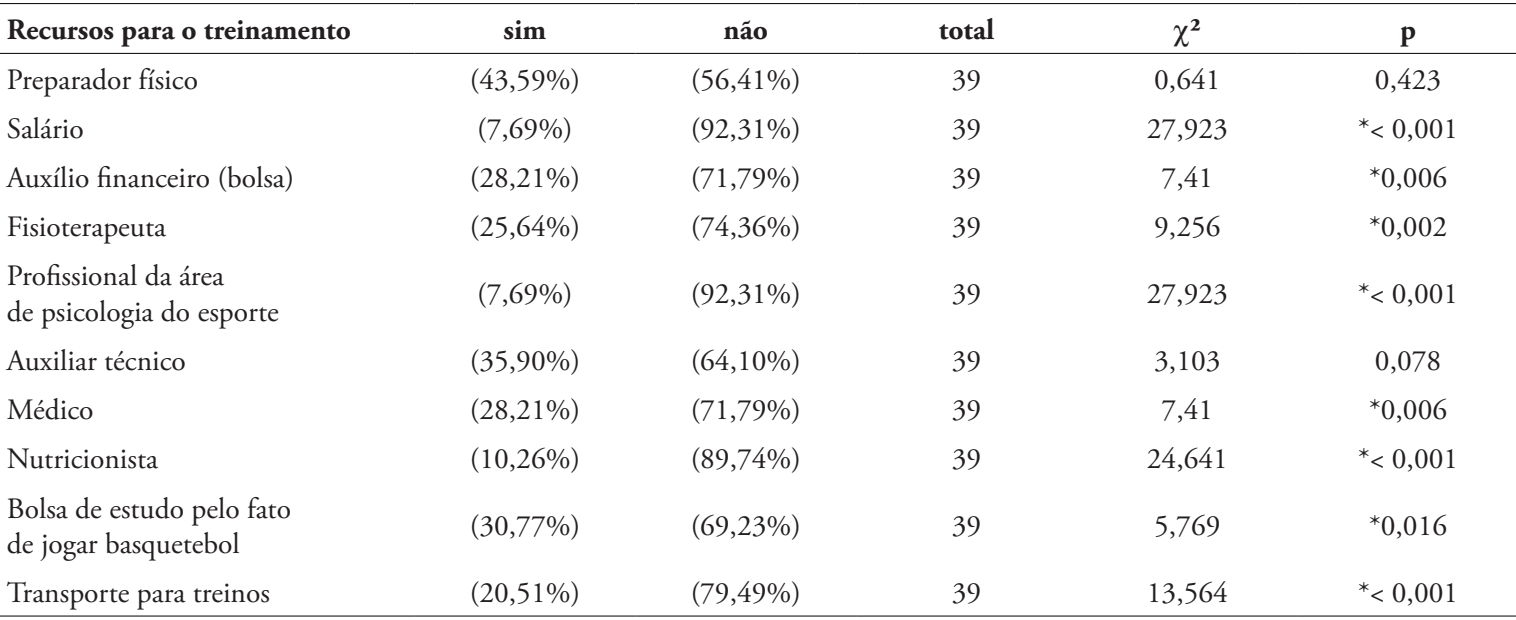

TABELA 6 - Distribuição dos atletas quanto aos recursos humanos efinanceiros para otreinamento de atletas debasquetebol da categoria sub-19 anos de Minas Gerais entre os 16 e 19 anos de idade e valores do teste de qui-quadrado.

\begin{tabular}{|c|c|c|c|c|c|}
\hline Recursos para o treinamento & $\operatorname{sim}$ & náo & total & $\chi^{2}$ & $\mathbf{p}$ \\
\hline Preparador físico & $(80,85 \%)$ & $(19,15 \%)$ & 47 & 17,9 & $*_{<}<0,001$ \\
\hline Salário & $(48,94 \%)$ & $(51,06 \%)$ & 47 & 0,02 & 0,884 \\
\hline Auxílio financeiro (bolsa) & $(40,43 \%)$ & $(59,57 \%)$ & 47 & 1,72 & 0,189 \\
\hline Fisioterapeuta & $(80,85 \%)$ & $(19,15 \%)$ & 47 & 17,9 & $*_{<}<0,001$ \\
\hline $\begin{array}{l}\text { Profissional da área } \\
\text { de psicologia do esporte }\end{array}$ & $(29,79 \%)$ & $(70,21 \%)$ & 47 & 7,68 & ${ }^{*} 0,006$ \\
\hline Auxiliar técnico & $(42,55 \%)$ & $(57,45 \%)$ & 47 & 1,04 & 0,307 \\
\hline Médico & $(59,57 \%)$ & $(40,43 \%)$ & 47 & 1,72 & 0,189 \\
\hline Nutricionista & $(25,53 \%)$ & $(74,47 \%)$ & 47 & 11,3 & $*^{*}<0,001$ \\
\hline $\begin{array}{l}\text { Bolsa de estudo pelo fato } \\
\text { de jogar basquetebol }\end{array}$ & $(48,94 \%)$ & $(51,06 \%)$ & 47 & 0,02 & 0,884 \\
\hline Transporte para treinos & $(68,09 \%)$ & $(31,91 \%)$ & 47 & 11,3 & $*^{*}<0,001$ \\
\hline
\end{tabular}

TABELA 7 - Distribuição dos atletas quanto aos recursos humanos e financeiros para o treinamento de atletas de basquetebol da categoria sub-19 anos de Minas Gerais e atletas profissionais entre os seis e 13 anos de idade e valores do teste de qui-quadrado.

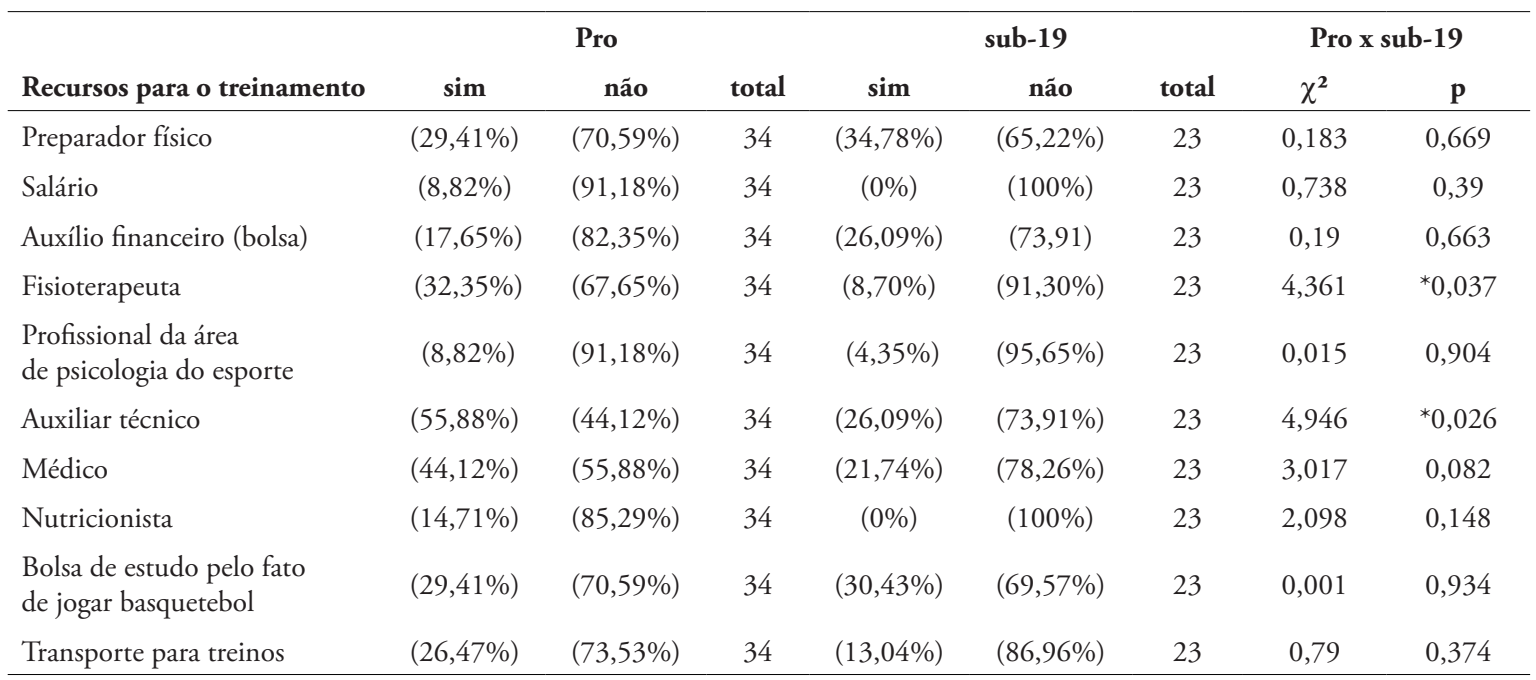

496 • Rev Bras Educ Fís Esporte, (São Paulo) 2014 Jul-Set; 28(3):491-503 
TABELA 8 - Distribuição dos atletas quanto aos recursos humanos e financeiros para o treinamento de atletas de basquetebol da categoria sub-19 anos de Minas Gerais e atletas profissionais entre os 14 e 15 anos de idade e valores do teste de qui-quadrado.

\begin{tabular}{|c|c|c|c|c|c|c|c|c|}
\hline \multirow[b]{2}{*}{ Recursos para o treinamento } & \multicolumn{3}{|c|}{ Pro } & \multicolumn{3}{|c|}{ sub-19 } & \multicolumn{2}{|c|}{ Pro x sub-19 } \\
\hline & $\operatorname{sim}$ & náo & total & $\operatorname{sim}$ & náo & total & $\chi^{2}$ & $\mathbf{p}$ \\
\hline Preparador físico & $(65,91 \%)$ & $(34,09 \%)$ & 44 & $(43,59 \%)$ & $(56,41 \%)$ & 39 & 4,169 & ${ }^{*} 0,041$ \\
\hline Salário & $(18,18 \%)$ & $(81,82 \%)$ & 44 & $(7,69 \%)$ & $(92,31 \%)$ & 39 & 1,979 & 0,16 \\
\hline Auxílio financeiro (bolsa) & $(36,36 \%)$ & $(63,64 \%)$ & 44 & $(28,21 \%)$ & $(71,79 \%)$ & 39 & 0,627 & 0,428 \\
\hline Fisioterapeuta & $(50 \%)$ & $(50 \%)$ & 44 & $(25,64 \%)$ & $(74,36 \%)$ & 39 & 5,178 & ${ }^{*} 0,023$ \\
\hline $\begin{array}{l}\text { Profissional da área } \\
\text { de psicologia do esporte }\end{array}$ & $(13,64 \%)$ & $(86,36 \%)$ & 44 & $(7,69 \%)$ & $(92,31 \%)$ & 39 & 0,266 & 0,606 \\
\hline Auxiliar técnico & $(59,09 \%)$ & $(40,91 \%)$ & 44 & $(35,90 \%)$ & $(64,10 \%)$ & 39 & 4,454 & ${ }^{*} 0,035$ \\
\hline Médico & $(36,36 \%)$ & $(63,64 \%)$ & 44 & $(28,21 \%)$ & $(71,79 \%)$ & 39 & 0,627 & 0,428 \\
\hline Nutricionista & $(13,64 \%)$ & $(86,36 \%)$ & 44 & $(10,26 \%)$ & $(89,74 \%)$ & 39 & 0,018 & 0,893 \\
\hline $\begin{array}{l}\text { Bolsa de estudo pelo fato } \\
\text { de jogar basquetebol }\end{array}$ & $(40,91 \%)$ & $(59,09 \%)$ & 44 & $(30,77 \%)$ & $(69,23 \%)$ & 39 & 0,921 & 0,337 \\
\hline Transporte para treinos & $(45,45 \%)$ & $(54,55 \%)$ & 44 & $(20,51 \%)$ & $(79,49 \%)$ & 39 & 5,753 & ${ }^{*} 0,016$ \\
\hline
\end{tabular}

TABELA 9 - Distribuição dos atletas quanto aos recursos humanos e financeiros para o treinamento de atletas de basquetebol da categoria sub-19 anos de Minas Gerais e atletas profissionais entre os 16 e 19 anos de idade e valores do teste de qui-quadrado.

\begin{tabular}{|c|c|c|c|c|c|c|c|c|}
\hline \multirow[b]{2}{*}{ Recursos para o treinamento } & \multicolumn{3}{|c|}{ Pro } & \multicolumn{3}{|c|}{ sub-19 } & \multicolumn{2}{|c|}{ Pro x sub-19 } \\
\hline & $\operatorname{sim}$ & nâo & total & $\operatorname{sim}$ & náo & total & $\chi^{2}$ & $\mathbf{p}$ \\
\hline Preparador físico & $(89,36 \%)$ & $(10,64 \%)$ & 47 & $(80,85 \%)$ & $(19,15 \%)$ & 47 & 1,343 & 0,247 \\
\hline Salário & $(76,60 \%)$ & $(23,40 \%)$ & 47 & $(48,94 \%)$ & $(51,06 \%)$ & 47 & 7,693 & ${ }^{*} 0,006$ \\
\hline Auxílio financeiro (bolsa) & $(63,83 \%)$ & $(36,17 \%)$ & 37 & $(40,43 \%)$ & $(59,57 \%)$ & 37 & 5,158 & ${ }^{*} 0,023$ \\
\hline Fisioterapeuta & $(85,11 \%)$ & $(14,89 \%)$ & 47 & $(80,85 \%)$ & $(19,15 \%)$ & 47 & 0,301 & 0,583 \\
\hline $\begin{array}{l}\text { Profissional da área } \\
\text { de psicologia do esporte }\end{array}$ & $(23,40 \%)$ & $(76,60 \%)$ & 47 & $(29,79 \%)$ & $(70,21 \%)$ & 47 & 0,49 & 0,484 \\
\hline Auxiliar técnico & $(82,98 \%)$ & $(17,02 \%)$ & 47 & $(42,55 \%)$ & $(57,45 \%)$ & 47 & 16,433 & $*<0,001$ \\
\hline Médico & $(70,21 \%)$ & $(29,79 \%)$ & 47 & $(59,57 \%)$ & $(40,43 \%)$ & 47 & 1,167 & 0,28 \\
\hline Nutricionista & $(42,55 \%)$ & $(57,45 \%)$ & 47 & $(25,53 \%)$ & $(74,47 \%)$ & 47 & 3,032 & 0,082 \\
\hline $\begin{array}{l}\text { Bolsa de estudo pelo fato } \\
\text { de jogar basquetebol }\end{array}$ & $(40,43 \%)$ & $(59,57 \%)$ & 47 & $(48,94 \%)$ & $(51,06 \%)$ & 47 & 0,689 & 0,407 \\
\hline Transporte para treinos & $(46,81 \%)$ & $(53,19 \%)$ & 47 & $(68,09 \%)$ & $(31,91 \%)$ & 47 & 4,352 & ${ }^{*} 0,037$ \\
\hline
\end{tabular}

$\mathrm{Na}$ comparaçáo entre os grupos, os atletas profissionais possuíam mais determinados recursos nas correspondentes faixas etárias em relação aos atletas da categoria sub-19 anos de MG: entre os seis e 13 anos, fisioterapeuta (TABELA 7); 14 e 15 anos, preparador físico e fisioterapeuta (TABELA 8); dos 16 aos 19 anos salário e auxílio financeiro (TABELA 9). Os atletas profissionais tiveram mais acesso à auxiliar técnico para todas as faixas etárias, na comparação com os atletas da categoria sub-19 anos de MG (TABELAS 7, 8, 9). Mais atletas da categoria sub-19 anos recebiam transporte para os treinos cedido pelas instituiçóes esportivas a partir dos 16 anos de idade em relação aos atletas profissionais
(TABELA 9). Tal fato ocorreu, possivelmente, por boa parte dos atletas profissionais não precisaram de tal quesito por morar em repúblicas cedidas pelas instituiçôes esportivas, entre os 16 e19 anos.

Os atletas profissionais possuíam mais recursos humanos até os 16 anos de idade (preparador físico, fisioterapeuta) (TABELAS 7, 8), e mais recursos financeiros (salário e auxílio financeiro) depois dos 16 anos (TABELA 9). Além disso, os atletas profissionais tiveram mais acesso à presença de auxiliar técnico durante a carreira na categoria de base, na comparação com os atletas da categoria sub-19 anos de Minas Gerais (TABELAS 7, 8,9 ). Isso significa que os atletas profissionais treinaram em instituições mais estruturadas 
desde os anos de experimentação, e com isso tiveram a possibilidade de se preparar melhor tanto na parte física, técnica, tática e nutricional até os 19 anos.

Sobre os recursos materiais, os treinadores da categoria sub-19 anos de MG consideram que são razoáveis, com exceção de um treinador que avalia estes recursos em seu clube como de primeira linha. Porém, quatro dos cinco treinadores reclamaram da questão de ter que dividir os horários de uso do espaço de treinamento com outras categorias ou com outros esportes.

Hoje o clube, com bola nós não temos problema, mas temos muito problema quanto ao espaço. Porque nós temos duas quadras no clube, que treinam desde o minibasquetebol até o sub-17, mais o Handebol. Nós temos sete categorias, para trabalhar em duas quadras. $\mathrm{E}$ isso complica às vezes, por que os meninos treinam de manhã e de tarde. Isso é uns dos problemas que nos temos... (T1).

Existe apenas um clube com recursos de alto nível em Minas Gerais. O nosso clube tem, mas não tem. Mais acessórios estão chegando aos poucos. O básico para a prática do basquetebol nós temos... Várias categorias jogam no clube, de esportes diferentes. E é sempre um desafio encontrar quadras para todos (T2).

Quanto aos recursos humanos, apenas um treinador de MG considera que seu clube possui uma equipe de trabalho multidisciplinar. Os outros treinadores relatam que profissionais como fisioterapeuta, nutricionista, médico e preparador físico não trabalham diretamente com os atletas. Estes profissionais muitas vezes são chamados pelos clubes esporadicamente. No clube, nós temos um preparador físico, que só trabalha com a categoria sub-19 anos e adulto. Ele orienta os treinadores, para que eles trabalhem a parte física. Temos um psicólogo que trabalha praticamente com todas as categorias. O trabalho deleé bem sobrecarregado. Auxiliar técnico, em um jogo ou outro. Um treinador acompanha outra categoria, e faz este papel. Auxiliar técnico específico para cada categoria nós não temos. De vez em quando, um nutricionista vem para dar uma palestra para os pais. A gente quer montar uma equipe completa, mas não temos recursos para isso. Na parte médica, nós temos algumas pessoas que foram atletas nossos e atende os nossos atletas. Temos um convênio com uma clínica de fisioterapia, que quando precisa o atleta vai lá e faz. Mas o fisioterapeuta não faz um trabalho preventivo (T1).

Os recursos humanos aqui no clube são bem completos. $\mathrm{O}$ atleta tem acesso a toda gama de profissionais, de nutricionista, fisioterapeuta, médico, psicólogo do esporte, tudo para o bom desenvolvimento do atleta. Mas nos outros clubes, se um atleta machuca você não tem um seguro e meios de cuidar dele. Eu já vivi esta situação. Ele machuca e não tem a estrutura para recuperar, voltar à forma, e você tem que contar com a sorte. $\mathrm{O}$ assistente técnico é presente no jogo, mas não nos treinamentos. Tirando a equipe adulta, nenhuma outra equipe conta com isso. Eu acredito que se tivéssemos um auxiliar técnico, mesmo com as condiçōes ruins do esporte para pagá-los, seria importante, até porque o basquetebol é um esporte muito dinâmico, e ter mais olhares acerca do treinamento seria o ideal. $\mathrm{O}$ assistente faz o trabalho à parte, fazer scout, edição de vídeo, treinos extras (T5).

A fala dos treinadores corrobora com os dados quantitativos na questáo da presença de um auxiliar técnico. Vale lembrar que os atletas profissionais possuíam mais este recurso, em todas as faixas etárias, em relação aos atletas da categoria sub-19 anos de MG. Os clubes mineiros, geralmente, não possuem este profissional atuando diretamente com as equipes de categoria de base. Quando acontece um jogo, um treinador de outra categoria faz este papel.

Sobre os recursos financeiros, os treinadores mineiros consideram a categoria sub-19 anos extremamente dispendiosa. Por conta disso, muitas equipes no estado não conseguem uma estrutura financeira para manter equipes de atletas até os 19 anos de idade. Como mostrou a TABELA 6 as equipes mineiras oferecem ajuda de custo, bolsa de estudos ou transporte para os treinos nesta fase somente para alguns atletas. Apenas os atletas, na faixa etária dos 16 aos 19 anos, de uma equipe de Minas Gerais recebem salário, por jogarem na equipe profissional da instituição. Porém, como mostrou a TABELA 3 muitos atletas profissionais nesta fase já eram assalariados. A categoria sub-19 exige recursos. O clube tem que oferecer uma ajuda de custo para o atleta. Eles não chegam a ser profissionais, mas exige-se uma estrutura de trabalho melhor, pois eu diria o campeonato sub-19 anos é para quem pode, não para quem quer... Se o clube chegar nesta categoria com déficit, e tiver que contratar um time inteiro, se gasta muito mais dinheiro... Fala-se em valores de no máximo 300 reais por atleta. Então a gente oferece uma ajuda de custo melhor para que o menino tenha acesso a um tênis, a uma alimentação adequada. Suplementação. Mas não chega perto de um salário, até porque eles estão em formação ainda (T3). 
No sub-19 anos os atletas recebem uma ajuda de custo, mas o atleta desta categoria que treina e joga com o adulto já tem um contrato profissional, portanto com salário. A maioria dos atletas das categorias mais avançadas recebe ajuda para o transporte aos treinos, e recebem também alimentação juntamente com os funcionários, para aqueles que ficam muito tempo dentro do clube treinando (T5).

Os dados quantitativos mostraram que não é possível afirmar que a maior parte dos atletas da categoria sub-19 anos de MG e profissionais recebem bolsa de estudo pelo fato de jogar basquetebol, durante a categoria de base. Os treinadores do basquetebol mineiro citam a dificuldade dos clubes em dar este recurso para os atletas. Das cinco instituições investigadas, apenas uma equipe não fornece nenhum tipo de bolsa de estudos aos atletas.

Nós temos uma parceria com a escola, a forma que eu tenho de ajudar meu atleta é conseguir uma bolsa de estudo para ele, num colégio melhor. Mas nós sabemos que a escola não quer o aluno, quer o atleta. Se ele é bom de bola, ele vai estudar para fazer parte de time. Mas isso é muito reduzido, eu consigo seis, sete bolsas no máximo, para todos os atletas do clube. Eu tenho no clube treinando 60 atletas, eu consigo 10 por cento de bolsas (T1).

Um fator que atrapalha o basquetebol mineiro é a falta de oportunidades claras para que o atleta se torne jogador profissional no Estado. Conforme mostra a TABELA 10, quando os atletas profissionais pertenciam à categoria sub-19 anos, a maior parte de suas instituiçôes esportivas possuía equipes profissionais de basquetebol. O mesmo não acontece com os atletas da categoria sub-19 anos de MG. Para piorar o quadro, uma das duas equipes profissionais em Minas Gerais que disputam a NBB (Novo Basquete Brasil), principal competição do basquete nacional, não possuía equipe da categoria sub-19 anos em 2011 ${ }^{16}$.

TABELA 10 - Equipes sub-19 anos que possuíam equipe profissional de basquetebol.

\begin{tabular}{|c|c|c|c|c|c|c|c|}
\hline \multirow[b]{2}{*}{ Categoria } & \multirow[b]{2}{*}{ total } & \multirow[b]{2}{*}{$\operatorname{sim}$} & \multirow[b]{2}{*}{ não } & \multicolumn{2}{|c|}{ Pro x sub-19 } & \multicolumn{2}{|l|}{ sim $x$ náo } \\
\hline & & & & $\mathbf{x}^{2}$ & $\mathbf{p}$ & $\chi^{2}$ & $\mathbf{p}$ \\
\hline Pro & 47 & $(74,47 \%)$ & $(25,53 \%)$ & 28,88 & $*_{<}<0,001$ & 11,225 & $*_{0,001}$ \\
\hline Sub-19 & 47 & $(19,15 \%)$ & $(80,85 \%)$ & & & 17,884 & $*^{*}<0,001$ \\
\hline
\end{tabular}

$\mathrm{O}$ único treinador de Minas Gerais entrevistado que possui, em sua instituição, equipe profissional atuando na NBB (Novo Basquete Brasil), salienta a importância desta situação para a formação destes atletas. Além disso, outro treinador ressalta o pouco aproveitamento dos atletas mineiros da base em equipes profissionais de Minas Gerais, e com isso, muitos atletas abandonam o esporte ou migram para outros centros com o intuito de se tornarem atletas profissionais.

A facilidade dentro do clube é a possibilidade do atleta estar jogando mais de uma categoria, e jogar no adulto também. Atletas com potencial fazem aqui 50 jogos no ano. Ele pega muita experiência jogando na equipe profissional, pega jogos mais pesados. No dia-dia estes garotos treinam com atletas mais experientes (T1). Em Minas Gerais, nós temos dois times adultos. Da minha geração, quando ainda jogava, apenas um jogador das categorias de base das equipes mineiras foi aproveitado pelas equipes profissionais do estado. Os outros são vindos de fora, mas ninguém com nível de seleção. Os meninos têm que ir para o estado de São Paulo, talvez Rio de Janeiro, ou mesmo fora do país. A gente em Minas desperdiça muitos possíveis jogadores, e não formamos atletas profissionais. Os meninos mais novos que vislumbram uma oportunidade começariam a praticar o esporte, outros se dedicariam mais e não sairiam do esporte por enxergar um futuro promissor (T3).

\section{Discussão}

O objetivo deste estudo foi analisar os recursos humanos, financeiros e materiais de atletas de basquetebol nas categorias de base e a percepção dos treinadores sobre estes recursos no processo de formação dos atletas. Recursos humanos, materiais e financeiros adequados são a base para se estabelecer programas eficientes de desenvolvimento de atletas rumo à excelência esportiva ${ }^{2-4}$. Bloom ${ }^{10}$ e Moraes e Salmela ${ }^{4}$ e 
ERICSSON ${ }^{2}$ reforçam em seus estudos que vários fatores podem influenciar o abandono da prática, como a premência de tempo e falta de recursos adequados. Os atletas em Minas Gerais enfrentam problemas estruturais mais severos para treinar em comparação aos atletas profissionais, quando estes eram de categorias de base. Os treinadores mineiros ressaltam que há poucos recursos financeiros para desenvolver os atletas. As equipes enfrentam problemas para ceder bolsas de estudo, salário ou auxílio financeiro aos atletas. Além disso, quanto aos recursos materiais, nos clubes mineiros o espaço físico para a prática do basquetebol muitas vezes é escasso, já que a modalidade geralmente divide os horários das quadras e ginásios com outros esportes praticados nestas instituiçóes.

Entretanto, treinar em estruturas com poucos recursos não é exclusividade dos atletas de basquetebol em Minas Gerais. No Brasil como um todo, Moreira et al. ${ }^{17}$ afirmam que o basquetebol passa por sérios problemas estruturais, já que muitos clubes náo conseguem arcar com as despesas referentes à manutenção dos recursos necessários para o desenvolvimento adequado dos atletas, e há pouco apoio das instituiçóes governamentais. Muitas vezes as instituiçóes esportivas se sustentam com verbas referentes às mensalidades dos sócios e dos dividendos oriundos de escolinhas. Patrocínios são raros, já que o esporte olímpico no Brasil sofre pela carência de visibilidade na mídia ${ }^{18}$.

A falta de recursos para a prática esportiva aparece em vários cenários do esporte brasileiro, e não apenas no basquetebol mineiro. Atletas de futebol do interior de Minas Gerais muitas vezes precisam se mudar para a capital do Estado para poder ter a oportunidade de se tornar um profissional no futuro, já que na região de origem os clubes possuem uma estrutura deficitária para a prática esportiva ${ }^{19}$. Nadadores medalhistas olímpicos brasileiros foram treinar em universidades dos Estados Unidos em busca de recursos materiais e humanos extremamente especializados e de excelência, já que no Brasil os recursos eram escassos ${ }^{3}$. É fundamental que haja um aumento da quantidade e da qualidade dos recursos disponíveis para que o atleta mineiro tenha a oportunidade de se tornar um jogador de basquetebol profissional. Tal situação passa pelo maior apoio das instituiçóes governamentais e de uma organização mais profissional por parte das instituições esportivas. Sobre esta situação, MEIRA et al. ${ }^{20}$, ao investigarem a estrutura organizacional do esporte brasileiro, revelam que tal estrutura é ineficiente em fazer com que os recursos financeiros do Comitê Olímpico Brasileiro e do Ministério dos Esportes cheguem aos programas esportivos estaduais e regionais.

Contrapondo este contexto, Nunomura e OliVEIRA $^{7}$ ao investigarem o sistema de treinamento da seleção permanente de ginástica artística do Brasil constataram que o Centro de Treinamento da modalidade, construído em Curitiba, apresenta recursos de ponta para o desenvolvimento das atletas, como: treinadores estrangeiros, aparelhos de nível internacional, equipe multidisciplinar de apoio composto por médicos, fisioterapeutas, psicólogos, auxiliares técnicos e coordenadores. Tal infraestrutura deste centro de treinamento representa um marco para este esporte no país, já que a realidade da ginastica artística brasileira é caracterizada por locais de treinamento que não apresenta condiçóes adequadas no que se refere aos recursos ${ }^{8}$. Já os estudos e Côté et al. ${ }^{5}$ e JoHnson et al. ${ }^{6}$ mostram que atletas de ginástica artística do Canadá e nadadores olímpicos americanos se desenvolvem em um contexto de treinamento com os melhores recursos disponíveis. Tal situação é essencial para que estes indivíduos atinjam um alto nível de desempenho.

No que se diz respeito aos recursos humanos, os treinadores em Minas Gerais muitas vezes treinam as equipes sem terem em mãos os melhores recursos, como uma equipe multidisciplinar que os auxiliem no desenvolvimento dos jogadores. Para suprir ausências e demandas de outros profissionais é natural que o treinador possua várias obrigaçóes. A natureza complexa da tarefa de ser treinador desportivo implica na realização de funçóes igualmente complexas. Além de protagonizar papéis ligados à gestáo de atividades do treinamento, à preparaçáo de jogadores e ao desenvolvimento dos fatores ligados ao desempenho, o treinador tem, ao mesmo tempo, assumido funçôes de conselheiro, amigo, incentivador, professor, líder, gestor, empreendedor, psicólogo e preparador físico ${ }^{21}$. As exigências acerca do contexto do treinamento estáo cada vez mais elevadas, especializadas e sofisticadas, necessitando tanto de infraestrutura complexa quanto de equipes multidisciplinares, com profissionais de diferentes áreas ${ }^{3,5,8}$.

Porém, destaca-se a falta de dois profissionais que poderiam auxiliar o trabalho dos treinadores no desenvolvimento dos atletas: auxiliar técnico, já que para todas as faixas etárias os atletas da categoria sub-19 anos de MG tiveram menos acesso a este profissional em comparação aos atletas profissionais; profissional da área de psicologia do esporte, pois este profissional estava pouco presente no cotidiano de treinamento, tanto dos atletas profissionais e da categoria sub-19 anos de MG, durante a categoria de base. 
Os auxiliares técnicos são fundamentais para o desenvolvimento dos atletas. Estes profissionais estáo sempre em alerta para detectar possíveis erros no processo, e para ajudar o treinador na condução das equipes. Os treinadores observaram ao longo do tempo que é impossível ser responsável por todas as áreas. Com isso, o assistente técnico exerce funçôes específicas, como treinar um atleta individualmente, ajudar na preparação do ataque ou da defesa coletiva, observar equipes adversárias. $\mathrm{O}$ cargo de assistente técnico pode também ser uma fase de aprendizado para futuros treinadores. Muitos treinadores, antes de se tornarem profissionais de excelência, já trabalharam nesta função ${ }^{22}$.

Outro recurso humano que pode ajudar o treinador é o profissional da área de psicologia do esporte. Apenas um treinador entrevistado citou a presença de um profissional da área de psicologia do esporte acompanhando sua equipe sub-19 anos. Porém, este profissional não é exclusivo, e atende outras categorias do clube. A presença deste recurso humano foi pouco requisitada pelas instituiçôes esportivas em todas as fases do treinamento, tanto para os atletas profissionais, quanto para os atletas da categoria sub-19 anos de MG. Rodrigues ${ }^{22}$, ao pesquisar o trabalho de treinadores portugueses de basquetebol de alto nível, verificou que o profissional da área de psicologia do esporte é visto como um elemento externo à comissão técnica, trabalha à sombra e contribui apenas quando é solicitado. Além disso, os treinadores receiam que este profissional assuma um papel maior no comando da equipe que o próprio comandante, o treinador. Este profissional não é considerado pelas equipes, neste contexto, um fator decisivo para o sucesso esportivo. Contrapondo este cenário, Stambulova et al. ${ }^{23}$ verificaram que atletas olímpicos de saltos ornamentais, de patinação artística, de ginástica artística e rítmica possuem uma equipe de profissionais da área de psicologia do esporte para melhorar as condiçôes psicológicas destes indivíduos durante as competiçôes dos Jogos Olímpicos.

Contudo, a importância da presença do profissional da área de psicologia do esporte auxiliando o trabalho do treinador é indiscutível. Estes profissionais estudam cientificamente as pessoas e os seus comportamentos no contexto do esporte e dos exercícios físicos, e depois aplicam estes conhecimentos na prática. $\mathrm{O}$ profissional da área da psicologia do esporte tem como funçâo analisar as bases e os efeitos psíquicos das açóes esportivas, considerando por um lado a análise de processos psíquicos básicos (cognição, motivação, emoção) e, por outro, a realização de tarefas e práticas do diagnóstico e da intervenção. Este profissional busca, através de dados psíquicos e fisiológicos, além de aumentar o desempenho físico, preservar a saúde e o bem-estar do indivíduo ${ }^{24}$.

Quanto ao acesso dos atletas da categoria sub-19 anos de Minas Gerais às equipes profissionais, tais jovens se encontram em uma situação incômoda: a instituição esportiva na qual praticam o basquetebol, na maior parte das vezes, não possui um time profissional. Nas equipes profissionais existentes em Minas Gerais o aproveitamento dos atletas mineiros muitas vezes é diminuto. Com isso, geralmente este atleta ou abandona o treinamento, para estudar e trabalhar, ou precisa sair do estado para realizar o sonho de se tornar atleta profissional.

Os estudos retrospectivos e recordatórios têm sido utilizados para as análises do desenvolvimento de carreiras esportivas ${ }^{3,7-8}$. Entretanto uma limitação da técnica de coleta de dados utilizada no presente estudo é o fato de que questionários retrospectivos avaliam os recursos disponíveis para o treinamento na categoria de base através da memória dos atletas. Não houve a possibilidade de confrontar as informaçóes apresentadas pelo questionário usado no presente estudo com outras fontes de dados.

Dada as delimitaçóes e limitaçôes apresentadas, o presente estudo permite argumentar que os atletas profissionais tiveram acesso às instituiçôes mais estruturadas durante a categoria de base. Os atletas profissionais possuíam mais recursos humanos até os 16 anos de idade (preparador físico, fisioterapeuta), mais recursos financeiros (salário e auxílio financeiro) depois dos 16 anos. Entre os 14 e 15 anos, os atletas profissionais tiveram mais acesso ao transporte para os treinos cedidos pelas instituições esportivas. Além disso, os atletas profissionais tiveram mais acesso a presença de auxiliares técnicos durante sua carreira na categoria de base, na comparação com os atletas mineiros. Isso significa que os atletas profissionais treinaram em instituiçôes com mais recursos desde os anos de experimentação, e com isso tiveram a possibilidade de se preparar melhor tanto nos aspectos físico, técnico, tático e nutricional até chegarem aos 19 anos.

Os treinadores de Minas Gerais ressaltam que as instituiçôes esportivas do estado possuem dificuldade em fornecer uma equipe multidisciplinar que auxilie o trabalho do treinador. Também, de acordo com os entrevistados, os jogadores da categoria de base de Minas Gerais na maior parte das vezes náo recebem nenhum tipo de auxílio financeiro ou bolsa de estudos. A escassez de espaço físico 
para o treinamento da modalidade nas instituiçôes esportivas foi um dos fatores citados pelos treinadores que dificulta o treinamento com os atletas.

Os atletas mineiros geralmente treinam em instituiçóes, dos 16 aos 19 anos de idade, que não possuem equipes profissionais de basquetebol. Com isso, de acordo com a fala dos treinadores, muitos deles precisam sair do estado na tentativa de seguir uma carreira esportiva profissional, ou mesmo abandonam a prática.

\begin{abstract}
Human, financial and material resources of basketball athletes in the youth academy and coaches' perception of athletes' development

The aim of this study was to analyze human, financial and material resources of basketball athletes in the youth academy and coaches' perception about these resources in the development of young athletes. This study sample was composed by: 47 Under-19 athletes of Minas Gerais and their respective coaches and also 47 professional athletes. The instruments used were: Questionnaire about Context of Practice for Basketball Athletes ("OCP-Basq", in Portuguese), Resources for Training Version and semi-structured interview. Based on the results it could be understood that professional athletes have trained, since their sports initiation, in institutions with more resources than in comparison with Minas Gerais Under-19 athletes. Minas Gerais coaches point out precariousness in structuring of resources during young athletes formation and emphasize that there is a difficulty in the professional teams of the state to utilize players that stand out at youth level.
\end{abstract}

KeY wORDS: Basketball; Athletes; Physical education; Training.

\title{
Referências
}

1. Ericsson KA, Krampe RT, Tesch-Romer C. The role of deliberate practice in the acquisition of expert performance. Psychol Rev. 1993;100:363-406.

2. Ericsson KA. Recent advances in expertise research: a commentary on the contributions to the special issue. Appl Cognitive Psych. 2005;19:233-41.

3. Ferreira RM, Penna EM, Costa VT, Moraes LCCA. Nadadores medalhistas olímpicos: contexto do desenvolvimento brasileiro. Motriz. 2012;18:130-42.

4. Moraes LC, Salmela JH. Expertise no esporte: considerações contextuais In: Garcia ES, Lemos KLM. Temas atuais VII: educação física e esportes. Belo Horizonte: Health; 2003. v.7, p.159-72.

5. Côté J, Salmela JH, Trudel P, Baria A, Russell SJ. The coaching model: a grounded assessment of expert gymnastic coaches' knowledge. J Sport Exerc Psychol. 1995;17:1-17.

6. Johnson MB, Castillo Y, Sacks DN, Cavacos JR, Edmonds WA, Tenebaum G. Hard work beats talent until talent decides to work hard: coaches' perspectives regarding differentiating elite and non-elite swimmers. Int J Sports Sci Coach. 2008;3:417-30.

7. Nunomura M, Oliveira MS. Centro de excelência e ginástica artística feminina: a perspectiva dos técnicos brasileiros. Motriz: 2012;18:378-92.

8. Schiavon LM, Paes RR. Condiçóes dos treinamentos de ginastas brasileiras participantes de jogos olímpicos (19802004). Motriz. 2012;18:757-69.

9. CBB. Confederação Brasileira de Basketball. Competições. Rio de Janeiro: CBB; 2014. [citado 2 mar. 2014]. Disponível em: http://www.cbb.com.br/Competicoes/Index.

10. Bloom BS. Developing talent in young people. New York: Ballentine; 1985.

11. Côté J. The influence of the family in the development of talent in sport. Sport Psychol. 1999;13:395-417.

12. Fraser MT, Gondim SM. Da fala do outro ao texto negociado: discussóes sobre entrevistas qualitativas. Paidéia. 2004;14:139-52.

502 • Rev Bras Educ Fís Esporte, (São Paulo) 2014 Jul-Set; 28(3):491-503 
13. Côté J, Ericsson KA, Law MP. Tracing the development of athletes using retrospective interview methods: A proposed interview and validation procedure for reported information. J Appl Sport Psychol. 2005;17:1-19.

14. Mathinson S. Why Triangulate? Educ Res. 1988;7:13-7.

15. Tesch R. Qualitative research: analysis types and software tools. New York: Falmer; 1990. p.330.

16. LNB. Liga Nacional de Basquete. Novo Basquete Brasil: campeonatos. São Paulo: LNB; 2014. [2 mar. 2014]. Disponível em: http://lnb.com.br/campeonato/?z=1\&t=3.

17. Moreira M, Souza M, Oliveira PR. A velocidade de deslocamento do basquetebol. Rev Bras Ciênc Esporte. 2012; 24201-15.

18. Alves JA, Pieranti OP. O Estado e a formulação de uma política nacional de esporte no Brasil. RAE-eletron. 2007;6. Disponível em: http://www.scielo.br/scielo.php?pid=S1676-56482007000100002\&script=sci_arttext.

19. Moraes LC, Rabelo AS, Salmela JH. Papel dos pais no desenvolvimento de jovens futebolistas. Psicol Refl Crít. 2004; 17:211-22.

20. Meira TB, Bastos FC, Böhme, M T. Análise da estrutura organizacional do esporte de rendimento no Brasil: um estudo preliminar. Rev Bras Educ Fís Esporte. 2012;26:251-62.

21. Ramos V, Graça AB, Nascimento JV, Silva R. A aprendizagem profissional - as representaçóes de treinadores desportivos de jovens: quatro estudos de caso. Motriz. 2011;17:280-91.

22. Rodrigues FE. O treinador: conhecimento e concepçóes de treino dos treinadores experts em basquetebol [dissertação]. Porto (PT): Universidade do Porto, Faculdade de Desporto; 2007.

23. Stambulova N, Stambulov A, Johnson U. Believe in yourself, channel energy, and play your trumps': olympic preparation in complex coordination sports. Psychol Sport Exerc. 2012;13:679-86.

24. Samulski DM. Introdução à psicologia do esporte. In: Samulski DM, organizador. Psicologia do esporte: conceitos e novas perspectivas. 2a ed. Barueri: Manole; 2009.

\begin{tabular}{|c|c|}
\hline $\begin{array}{r}\text { ENDEREÇo } \\
\text { Varley Teoldo da Costa } \\
\text { Laboratório de Psicologia do Esporte } \\
\text { Escola de Educação Física, Fisioterapia e Terapia Ocupacional } \\
\text { Universidade Federal de Minas Gerais } \\
\text { Av. Pres. Carlos Luz, } 4664 \\
31310-250 \text { - Belo Horizonte - MG - BRASIL } \\
\text { e-mail: vtcosta@hotmail.com }\end{array}$ & $\begin{array}{l}\text { Recebido para publicação: 19/10/2012 } \\
\text { 1a. Revisão: 17/03/2014 } \\
\text { 2a. Revisão: 21/04/2014 } \\
\text { 3a. Revisão: 05/06/2014 } \\
\text { Aceito: 09/o6/2014 }\end{array}$ \\
\hline
\end{tabular}

